\title{
Liberation of iris pigment in the anterior chamber
}

\section{After instillation of ro per cent. phenylephrine hydrochloride solution}

\author{
J. L. AGGARWAL AND B. BEVERIDGE
}

Wolverhampton and Midland Counties Eye Infirmary

Phenylephrine hydrochloride is a topical mydriatic widely used in clinical practice. Its action is due to a direct sympathomimetic effect upon the myoneural junction, resulting in mydriasis, slight cycloplegia, an increase in the facility of aqueous outflow, and constriction of the conjunctival vessels. The ro per cent. aqueous solution is commonly used, but reaction has been observed after the instillation of solutions as weak as $0 \cdot 125$ per cent. (Havener, I 966) and o. I per cent. (Haddad, Moyer, and Riley, I970), which is enhanced by increased absorption after trauma to the corneal epithelium. One side-effect of its action is the liberation of pigment granules into the aqueous 30 to 40 minutes after instillation, a phenomenon first described by Mitsui and Takagi (196r), who observed that it occurred in 4.6 per cent. of subjects after the instillation of a 5 per cent. solution. The majority of these subjects were middle-aged or elderly, and it was shown that the pigment granules had the same characteristics as those in the cells of the iris neuroepithelium. Haddad and others (1970) observed similar aqueous floaters in a high proportion of subjects over the age of $5^{0}$ years after the instillation of I per cent. and commercial io per cent. solutions Biggs, Alpern, and Bennett (1959) observed similar floaters after the subconjunctival injection of epinephrine, and Chamlin ( 1959) observed them in cases of papillitis and drew attention to the diagnostic confusion which may follow the instillation of mydriatics in these cases.

The present study was begun after the frequent chance observation of aqueous floaters in eyes into which ro per cent. phenylephrine hydrochloride drops had been instilled before routine fundus examination. During a period of two months, i 50 patients were examined biomicroscopically both before and after dilatation of the pupils with ro per cent. phenylephrine hydrochloride solution.

In forty cases ( 27 per cent.) an aqueous flare and floaters were observed after dilatation of the pupils; in some cases "Novesine" (Benoxinate hydrochloride 0.4 per cent.) had also been instilled.

\section{Method}

(I) PRELIMINARY STUDY

A random selection of 150 patients ( 73 males and 77 females) ranging in age from 12 to 86 years attending routine Out-patient Clinics had mydriatics instilled into both eyes before ophthalmoscopy. 
A 10 per cent. solution of phenylephrine hydrochloride B.P. in sterile aqueous solution, with benzalkonium chloride B.P. $0 \cdot 04$ per cent. as antiseptic, was instilled once into both eyes of each patient; cases of suspected optic neuritis, diabetes, uveitis in any form, and those with abnormal anterior segments were excluded from the study.

Of the 150 patients studied, forty (27 per cent.) between the ages of 43 and 86 were found to have developed an aqueous flare and floaters in both eyes. Patients exhibiting occasional floaters were not re-examined. No floaters were seen in any of the patients between the ages of 12 and 43 years. These results are summarized in Fig. I.

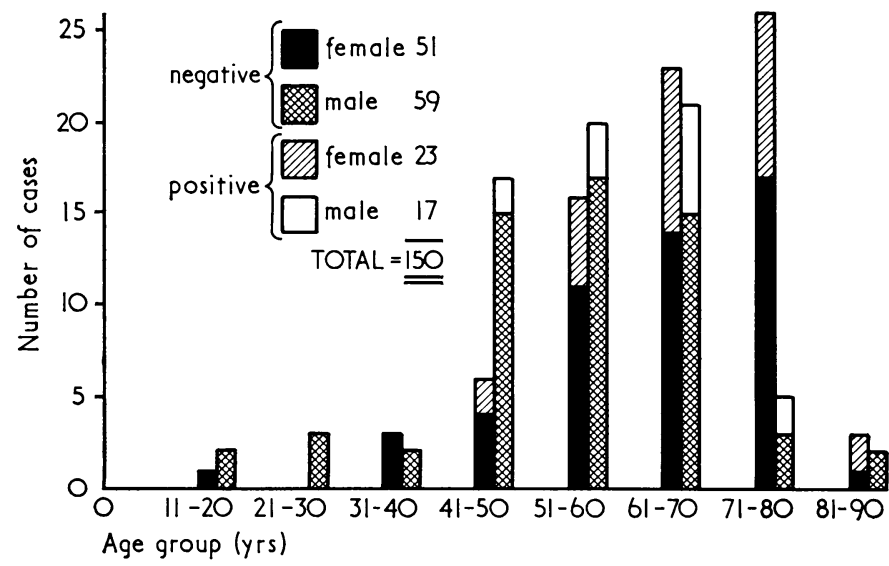

FIG. I Age and sex distribution of 150 patients examined after instillation of phenylephrine hydrochloride. Those who exhibited pigment liberation are shown as positive

Table I Age and sex distribution of forty patients showing pigment liberation after instillation of ro per cent. phenylephrine hydrochloride

\begin{tabular}{|c|c|c|c|}
\hline Age (yrs) & Male & Female & Total \\
\hline $4^{I-50}$ & 2 & 2 & 4 \\
\hline $5^{1-6 o}$ & 3 & 5 & 8 \\
\hline $61-70$ & 6 & 9 & 15 \\
\hline $71-80$ & 2 & 9 & I I \\
\hline $8 \mathbf{I}-90$ & - & 2 & 2 \\
\hline Total & 13 & 27 & 40 \\
\hline
\end{tabular}

\section{(2) DETAILED STUDY OF PIGMENT LIBERATION}

The forty patients in whom pigment liberation had been observed were recalled for more detailed examination to determine whether any common factor other than age could be found. The age and sex distribution is shown in Table I. Io per cent. phenylephrine hydrochloride drops were instilled into both eyes three times at 5 -min. intervals.

Pigment liberation was seen to start 30 to 45 minutes after the first instillation of drops, reaching a maximum $\mathrm{I}$ to 2 hours after instillation, and gradually disappearing after 24 hours.

In each case the following details were noted: age, sex, iris colour, and intraocular pressure and gonioscopic appearances before and after dilatation of the pupil. I $\frac{1}{2}$ hours 
after the pupil had become fully dilated (with liberation of pigment) 4 per cent. pilocarpine nitrate drops were instilled into each eye, and the eyes were re-examined when the pupils had become constricted.

\section{Results}

IRIS GOLOUR

The main iris colour was noted and classified by the categories described by Riddell ( 1942 ).

The results are shown in Table II.

Table II Distribution of iris colour (Riddell, 1942)

\begin{tabular}{|c|c|}
\hline Colour & No. of patients \\
\hline I Blue & Io (6 male, 4 female) \\
\hline 2 Grey & Io (6 male, 4 female) \\
\hline 3 Green & 6 (6 female) \\
\hline 4 Yellow & None \\
\hline $5 \operatorname{Tan}$ & 14 (I male, 13 female) \\
\hline 6 Chocolate & None \\
\hline
\end{tabular}

Table III Range of fall in intraocular $\vec{\omega}$ pressure in thirty cases

Fall in intraocular pressure $(\mathrm{mm} . \mathrm{Hg}$ )

$0-5$

No. of cases

$5^{-10}$

8

10-15

15-20

INTRAOGULAR PRESSURE

In six patients there was no change in intraocular pressure in response to to per cent. phenylephrine hydrochloride.

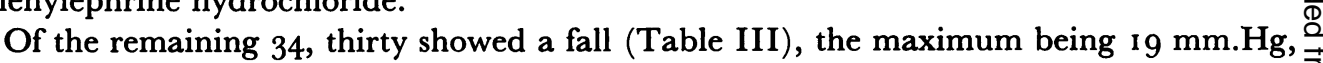
and four showed a rise.

Of the four cases showing a rise, three rose by only $\mathrm{I}$ to $3 \mathrm{~mm} . \mathrm{Hg}$; the quantity of pigment liberated into the anterior chamber in these cases was not significantly greater than that observed in the cases showing a fall in pressure.

The one remaining case was that of a 71 -year-old woman with occlusion of a retinal tributary vein, who was found to have chronic simple glaucoma (gonioscopy showed 3 Grade $0-1$ angles). In this case there was a rise in intraocular pressure of $6 \mathrm{~mm}$. in one eye and I $\mathrm{mm}$. in the other.

\section{GONIOSCOPY}

Of the eighty eyes examined, nine showed an abnormally large amount of pigment in the $\mathbb{N}$ angle before the instillation of phenylephrine. After dilatation of the pupils and liberation $N$ of pigment, no increase in the amount of pigment was seen in any case. In several cases ${ }_{\mathrm{C}}^{N}$ the angle appeared to be wider after dilatation of the pupil than before.

IRIS PIGMENT LIBERATION

This was observed in all the eighty eyes examined, but varied in intensity. For ease of $\frac{0}{0}$ identification, three grades were devised, corresponding to grades 4, 5, and 6 of Mitsui's scale of floaters (1943). 
+ A mixture of pigmented and non-pigmented floaters in one section of the slitlamp beam. (Io cases).

++ Hundreds of pigmented floaters in one section of the slit-lamp beam, sometimes forming laminated patterns; these cases tended to overlap with the next grade (13 cases).

+++ Innumerable pigmented floaters in one section of the slit-lamp beam. Sometimes these were laminated and sometimes they took on the appearance of a pigmented veil or curtain ( 17 cases).

In some of the cases in the last group, the manner in which pigment was liberated took on certain distinct patterns.

(i) A cloud of pigmented floaters at the pupil margin (Figs 2 and 3)
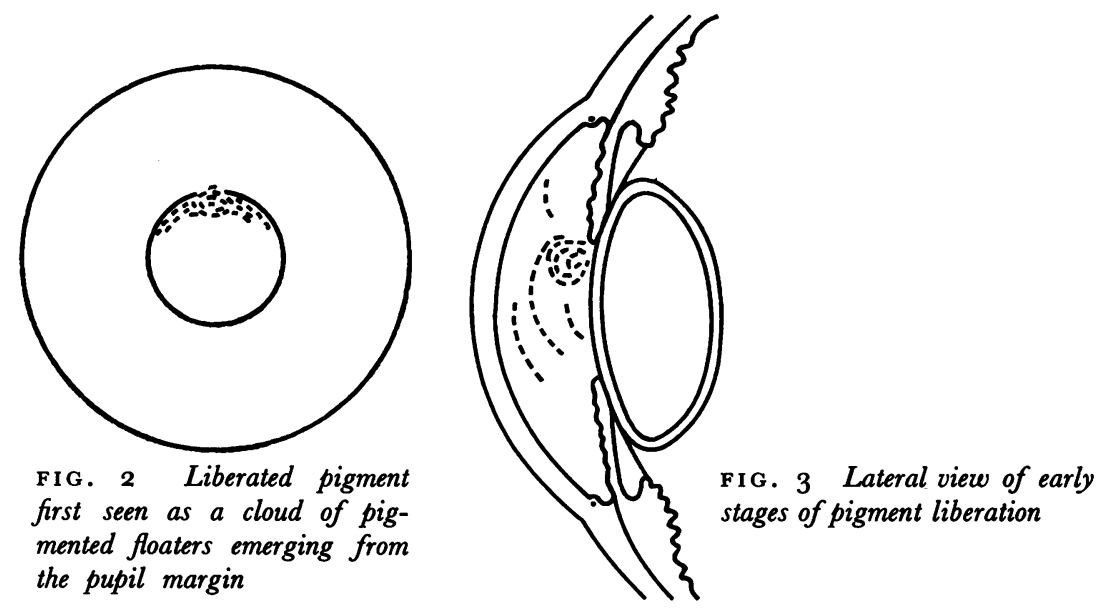

(ii) Laminae of floaters, most marked I-2 mm. posterior to the corneal endothelium (Fig. 4)
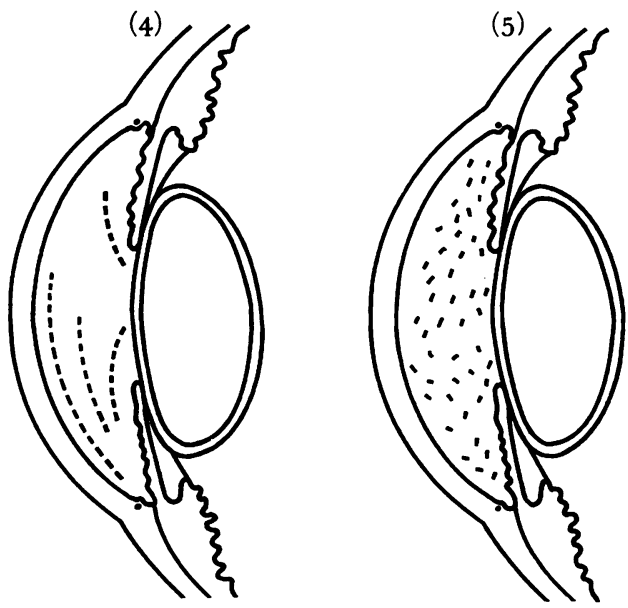

FIG. 4 Liberated pigment takes the form of laminae closely related to the posterior corneal surface (lateral view)

FIG. 5 There is a faint flare in the anterior chamber, which is filled with innumerable pigmented floaters (lateral view)

(iii) A faint flare and innumerable pigmented floaters filling the anterior chamber (Fig. 5)

(iv) A "curtain" of pigment particles across the pupil. 
All these patterns were observed in different eyes; they were quite distinct from each other and there was no progression from one pattern to another.

RE-EXAMINATION

After constriction of the pupils with 4 per cent. pilocarpine nitrate solution, each patient was re-examined biomicroscopically. At this stage it was found that the amount of pigment liberated had increased still further. The pigment disappeared during the ensuing 24 hours.

\section{Discussion}

Pigment liberation into the anterior chamber after the instillation of mydriatics is a well-known phenomenon, and the findings of the present study confirm this, particularly in respect of phenylephrine hydrochloride. No significant discovery emerged from this study, except that the great majority of patients in which pigment liberation was observed were over 40 years old, which confirms the findings of other workers. The observation is of clinical importance, because phenylephrine is now widely used in ophthalmology and this pigment liberation may be confused with anterior uveitis or with a microscopic hyphaema. It is important, therefore, when contemplating the use of phenylephrine to examine the patient's eyes biomicroscopically before it is instilled to ascertain the presence or absence of aqueous floaters. If pigment liberation should occur afterwards, the fact should also be recorded as a warning to unwary future examiners. It is possible to distinguish mydriatic-induced floaters from those of iritis by careful examination; the former are larger and pigmented, whereas the latter are smaller and greyish in appearance. The patterns of pigment liberation are possibly related to variations in the viscosity of the aqueous, so that when this is increased (as in pattern iii) there is cessation of its circulatory stream. None of the patients examined experienced any symptoms from the presence of floaters and in all cases the floaters disappeared without any treatment; no evidence was found of the presence of free erythrocytes in the anterior chambers of any of the eyes examined.

The mechanism by which pigment granules are liberated is probably that postulated by Mitsui and Takagi (1961), i.e. they originate from degenerate cells of the pigment epithelium of the iris which rupture during contraction of the dilator pupillae. The degeneration of these cells is thought to be a senile change and angiosclerosis is a predisposing factor. The phenomenon of rebound miosis after phenylephrine mydriasis recently described by Haddad and others (1970) suggests that the dilator muscle may also be damaged and that this may be an additional source of floaters. The relatively high incidence of pigment liberation in the present study (27 per cent.) as compared with that found by Mitsui and Takagi (I96I) may be the result of our having used a stronger No solution of phenylephrine hydrochloride (ro per cent.), inducing a greater contraction of the dilator pupillae with more extensive cellular damage. The further increase of pigment liberation which followed the instillation of pilocarpine may be a mechanical effect of stretching the damaged epithelium.

Our observations are similar to those of previous workers, with one exception. No notable increase in trabecular pigmentation was found on gonioscopy after pigment $\stackrel{\mathcal{S}}{\rightarrow}$ liberation, and in some cases the width of the angle appeared to increase. In thirty of $\frac{0}{3}$ the cases examined, the usual fall in intraocular pressure was observed after the instillation $\mathbb{\mathbb { D }}$ of phenylephrine; the exact mechanism whereby this fall occurs remains unknown. In in $\infty$ 
the one case of chronic simple glaucoma previously mentioned there was a rise in intraocular pressure, a rare occurrence which has previously been reported by Lee (1958) and Hill (1968). This paradoxical response may possibly be attributed to blockage of an already embarrassed trabecular meshwork by liberated pigment granules.

\section{Summary}

During a period of 2 months, $15^{\circ}$ patients were examined after the instillation of ro per cent. phenylephrine drops as a routine mydriatic before ophthalmoscopy. Forty of these (27 per cent.) were found to develop a flare and aqueous floaters 30 to 45 minutes later because of liberation of iris pigment; some showed characteristic patterns. No significant common factor was found except that all were over 40 years old and no symptoms were experienced. The effect of phenylephrine on the intraocular pressure and the angle were also noted. There is a danger of confusing this relatively harmless phenomenon with anterior uveitis; it is probably caused by damage to the iris pigment epithelium.

We wish to thank Mr. A. Hirtenstein, Mr. D. F. Woodhouse, Mr. B. R. Kesby, and Mr. A. W. Sollom for their advice and for allowing us to examine their patients, and Dr. M. Paul for his help with the illustrations.

\section{References}

Biggs, R. D., ALPERn, M., and Bennett, D. R. (i959) Amer. F. Ophthal., 48, i69

Chamlin, м. (1959) A.M.A. Arch. Ophthal., 6r, 37

hADDAD, N. J., moyer, N. J., and Riley, f. c. (1970) Amer. F. Ophthal., 7o, 729

havener, W. H. (1966) “Ocular Pharmacology”, pp. I89-194. Mosby, St. Louis

HILl, K. (I968) Arch. Ophthal. (Chicago), 79, 804

LEE, P. F. (1958) Ibid., 6o, 863

мitsui, y. (1943) Acta Soc. ophthal. jap., 47, I6

- and takagi, y. (ig6i) Arch. Ophthal. (Chicago), 65, 626

RIDDELL, w. J. B. (1942) Trans. ophthal. Soc. U.K., 62, I83 